\title{
Hair Shaft Yellow Nodules in a Pediatric Female Patient
}

\author{
Cecilia Sandoval-Tress ${ }^{a}$ Roberto Arenas-Guzmán ${ }^{b}$ \\ Daniela Araucaria Guzmán-Sánchez ${ }^{\mathrm{c}}$ \\ a Dermatology Department, Hospital General de Zona 42 Instituto Mexicano del Seguro Social (IMSS), \\ Puerto Vallarta, ${ }^{\mathrm{b}}$ Micology Department, Hospital General Dr. Manuel Gea González, Mexico City, and \\ ' $d$ \& laser Clinic Dermatology and Laser Private Clinic, Guadalajara, Mexico
}

\section{Question}

A 7-year-old Mexican girl was referred to the Department of Dermatology at the Mexican Institute of Social Security for an 8-month history of an asymptomatic hair disorder.

Physical examination revealed the presence of multiple yellow sheaths firmly adhered to the hair shaft, measuring approximately $2-3 \mathrm{~mm}$ (fig. 1). Each hair shaft presented 4-5 nodular lesions more evident on her wet hair.

A direct examination with black chlorazol and a culture on Sabouraud agar were performed. Black chlorazol examination showed septate hyphae and arthroconidia (fig. 2) as well as Sabouraud culture yeast colonies with a brain-shaped appearance that were identified as Trichosporon spp.

The affected hairs were examined by dermoscopy that showed fusiform and yellow nodules of Trichosporon spp. around the hair shaft and attached to the distal parts of the hair (fig. 3).

The patient was treated with itraconazole $100 \mathrm{mg} /$ day and topical selenium sulfur shampoo with good clinical and mycological response after 2 months of treatment.

What is your diagnosis? 
Fig. 1. Multiple yellow nodules around the hair shaft.

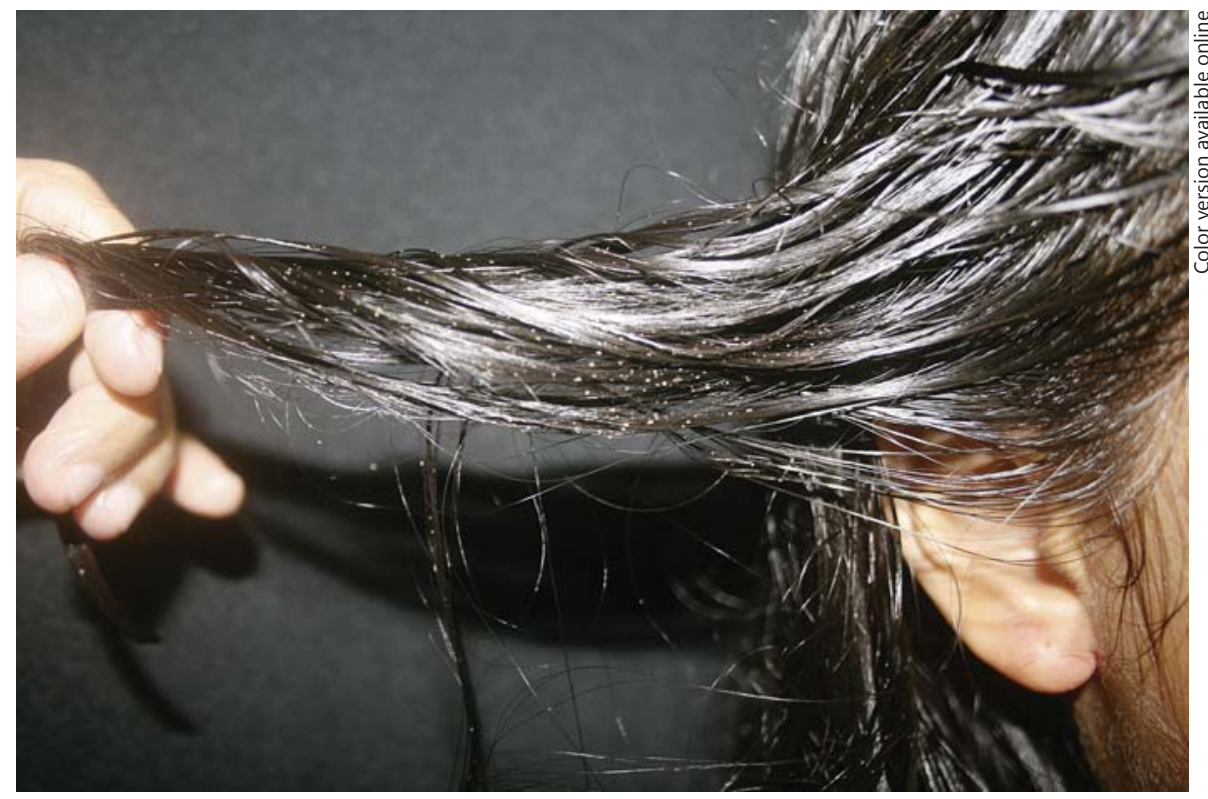

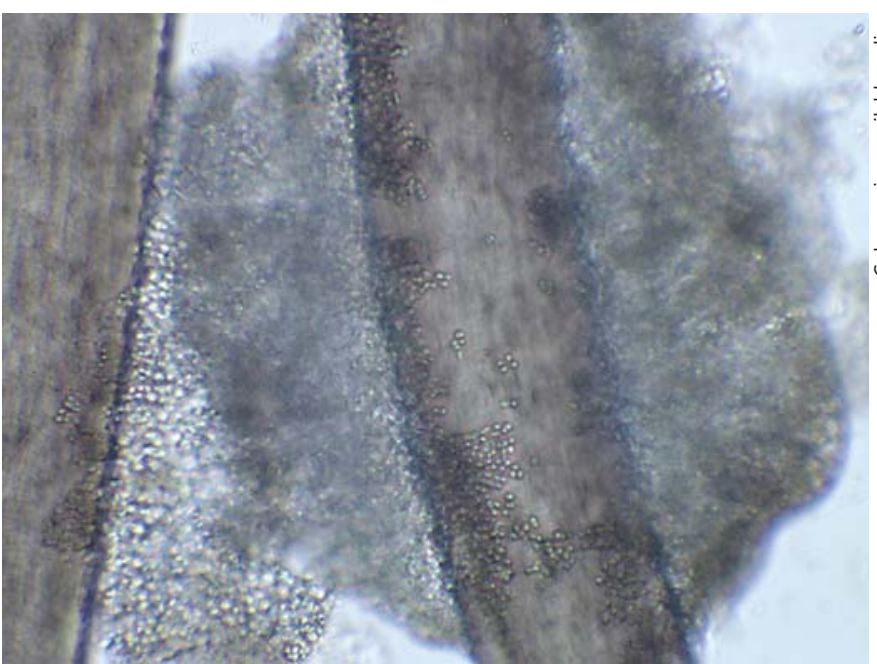

Fig. 2. Black chlorazol examination showing the presence of arthroconidia $(\times 40)$.

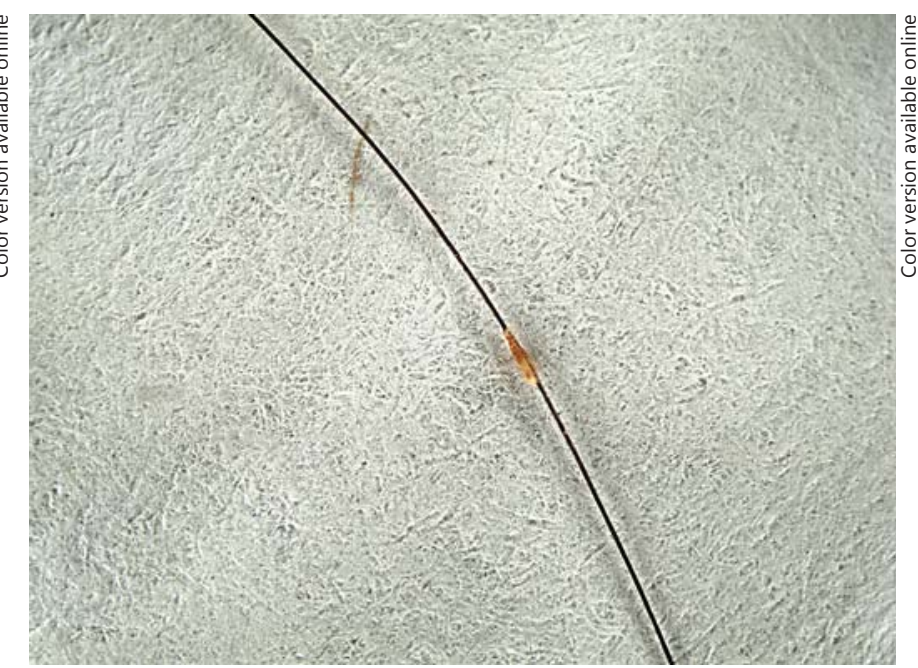

Fig. 3. Hair shaft coated by yellow sheaths $\left(\right.$ TrichoScan $\left.{ }^{\circledR}\right)$. 


\section{Answer}

White piedra infection.

White piedra is a superficial mycosis caused by yeastlike organisms of the genus Trichosporon that usually affects the hair shaft of the beard, moustache, genitals, axilla and scalp, and it is frequently asymptomatic [1].

Trichosporon spp. was first described by Beigel in 1865 [2], and in 1890, Behrend coined the genus name [3]. To date, six different species of Trichosporon (T. cutaneum, T. ovoides, T. inkin, T. asahii, T. asteroides and T. mucoides) have been described, the first three being the most common causal agents [4].

In Mexico, white piedra is more frequent in pediatric female patients and usually affects the scalp hair. Risk factors are braiding the hair, the use of hairstyling products such as gels or sprays and grabbing the hair when it is still wet. Most of the cases have been reported in tropical regions with high temperatures and humidity that predispose to fungal infections [5].

There have been reports of outbreak in children attending day care centers [6] and in association with other scalp infestations such as pediculosis $[6,7]$.

Diagnosis should be suspected clinically and corroborated by mycologic studies, direct examination and isolation of the causal agent. Dermoscopy allows a diagnosis from hair shaft abnormalities such as trichorrhexis nodosa, monilethrix and hair cast [8]. Other differential diagnoses that should be considered are trichomycosis, pediculosis, scalp tinea, folliculitis and seborrheic dermatitis.

Dermoscopy of trichorrhexis nodosa exposes white nodules and brushlike ends (fractured and frayed ends), monilethrix shows hair shaft beading caused by the presence of nodes (containing medulla) and internodes (no medulla) as well as the bended ribbon sign, parakeratotic hair cast presents as white to yellow scales or masses of scales of irregular shape and size loosely attached to hair shafts but also affects the interfollicular scalp, and traction hair cast presents as white to brown cylindrical structures that encircle the proximal hair shafts, whereas hair and deodorant sprays, gel show grayish white sleevelike structures [8].

Treatment includes shaving or clipping of the infected hairs. Topical antifungals such as $30 \%$ salicylic acid solution, $2 \%$ zinc pyrithione, selenium sulfur and imidazoles (econazole, isoconazole, miconazole and ketoconazole) are recommended. Oral itraconazole and fluconazole have shown to be effective therapeutic agents. The combination of oral azole antifungals and shampoos is highly recommended $[1,9,10]$.

Dermoscopy is a fast, noninvasive and cost-efficient technique for the diagnosis of hair shaft disorders such as white piedra, although mycological examination should always be performed to confirm the diagnosis.

\section{Statement of Ethics}

The authors have no ethical conflicts to disclose.

\section{Disclosure Statement}

The authors have no conflicts of interest to declare.

\section{Key Words}

Dermoscopy · Trichosporon spp. · Superficial mycoses

\section{References}

1 Bonifaz A, Gómez-Daza F, Paredes V, Ponce RM: Tinea versicolor, tinea nigra, white piedra, and black piedra. Clin Dermatol 2010;28: 140-145.

2 Negroni R: Historical aspects of dermatomycosis. Clin Dermatol 2010;28:125-32.

3 Guého E, de Hoog GS, Smith MT: Neotypification of the genus Trichosporon. Antonie Van Leeuwenhoek 1992;61:285-288.

4 Arenas R: Piedras; in Arenas R: Micología Médica Ilustrada. México, McGraw-Hill, 2008, pp 106-112.
5 Romero-Navarrete M, Arenas-Guzmán R, Castillo-Solana A: Piedra blanca. Informe de tres casos en Acapulco, Guerrero, México. DCMQ 2009;7:109-112.

6 Roselino AM, Seixas AB, Thomazini JA, Maffei CM: An outbreak of scalp white piedra in a Brazilian children day care. Rev Inst Med Trop Sao Paulo 2008;50:307-309.

7 Marques SA, Richini-Pereira VB, Camargo RM: White piedra and pediculosis capitis in the same patient. An Bras Dermatol 2012;87: 786-787.
8 Miteva M, Tosti A: Dermatoscopy of hair shaft disorders. J Am Acad Dermatol 2013;68: 473-481.

9 Kiken DA, Sekaran A, Antaya RJ, Davis A, Imaeda S, Silverberg NB: White piedra in children. J Am Acad Dermatol 2006;55:956-961. 10 Ríos X, Rojas RF, Hincapié ML: Ocho casos de piedra blanca en población pediátrica. Rev Asoc Colomb Dermatol 2012;20:175-180. 